\title{
HUNTING SONG OF THE KAYAK-PADDLER
}

When I go out alone

In my kayak

Singing the walrus song

Aiy Aiy Aiy $\mathbf{O}$

When I meet the walrus

Alone

Singing his kayak song

Aiy Aiy Aiy $\mathbf{O}$

When we hear each other

Singing

To the paddle's stroke

Aiy Aiy Aiy $\mathbf{O}$

When I lift up my lance

For the kill

And we eye each other

Aiy Aiy Aiy $\mathbf{O}$

O Walrus, Father, Food and Transportation

Lay your flippers down

And your teeth like long knives Wa wa

O Walrus, Father, Food and Transportation

Today I have come

To hunt the seal and caribou Wa wa

O Walrus, Father, Food and Transportation

At home a woman

Rubs herself with fat for me Wa wa

Aiy Aiy Aiy $\mathbf{O}$

Aiy Aiy Aiy $\mathbf{O}$ 